\title{
In Vivo Anti-Inflammatory and Antioxidant Potentials of Ethanolic Flower Extract and Isolated Compound, Rutin from Bauhinia tomentosa $\mathbf{L}$.
}

\section{Gargi Gangadharan* and K. Thenmozhi}

PG and Research Department of Botany, Kongunadu Arts and Science College, Coimbatore641 029, Tamilnadu.

*Corresponding author:

Email: gargigangadharan387@gmail.com 


\begin{abstract}
Bauhinia tomentosa L. belonging to the family Caesalpiniaceae is a traditional medicinal plant species used by the local healers for the treatment of inflammation and other ailments. The present study was addressed to isolate and characterize bioactive entities exists in the ethanolic extract of $B$. tomentosa flower. Moreover, the anti-inflammatory effects of crude and isolated compounds were assessed using carrageenan induced paw oedema model. Indomethacin, a renowned reference drug was used for comparison. In vivo antioxidant activities were achieved using standard procedures. In anti-inflammatory studies, the isolated compound, rutin (10mg/kgb.w.) manifested potent activity by inhibiting paw oedema $(92.6 \%)$ than the crude extracts $(88.7 \%)$. With reference to these findings, rutin also registered eminent therapeutic property in terms of in vivo antioxidant activity. Therefore, the current study exposed that the anti-inflammatory effects of isolated compound, rutin is more expected to depend on their ability to inhibit the production of proinflammatory mediators and proposes that the studied plant species can be deliberated as one of the finest, versatile and most frequently used household remedies for varied manifestations. Furthermore, the compound isolated may serve as a lead molecule for the formulation of active novel drugs without any adverse side effects.
\end{abstract}

Keywords: Bauhinia tomentosa, anti-inflammatory, rutin, paw oedema, in vivo antioxidant

\title{
Introduction
}

Inflammation is considered to be a leading physiological defence mechanism that benefits the body to defend themselves in contradiction of infection, toxic chemicals, allergens, burn or other noxious stimuli. Inflammation may perform as an etiologic element for the development of several chronic disorders and are closely associated ${ }^{1,2}$. Inflammation can be deliberated as a multifaceted interplay of cellular and particulate mediators, which includes chemokines, plasma enzymes, lipids and cytokines ${ }^{3}$. Presently, both steroidal antiinflammatory drugs and non- steroidal anti-inflammatory drugs (NSAIDS) are generally preferred for the treatment of inflammation. The abiding usage of oral nonsteroidal antiinflammatory drugs has several adverse effects comprising of gastrointestinal erosion, cardio vascular disorders, and renal adverse events ${ }^{4}$. To overwhelm these effects, numerous natural constituents, specifically from therapeutic herbs are an approach to ascertain novel antiinflammatory medications 5 . 
Bauhinia tomentosa L. is an eminent indigenous medicinal plant used in folkloric claim in tropical regions around the world, particularly in greater parts of India. It is generally known as 'Kanchini' in Tamil and 'Phalgu' in Sanskrit'. The dried leaves, flower, root, fruit and seed parts of this plant were used conventionally to indulge several ailments. The decoction of the root bark is a vermifuge to treat abdominal problems and as an antihelmintic agent. An infusion of the root bark is usually used as an external application for the management of inflammed glands, abscesses and skin conditions. The stem bark is employed as an astringent gargle. Flower is expended as a remedy for curing dysentery and hematuria. The fruit is diuretic, and an infusion of the rind is used as an astringent gargle ${ }^{7}$. The seed is consumed as tonic, aphrodisiac and paste of the seed is assorted with vinegar to treat wounds procreated by venomous animals. Decoction of the root bark is recommended as a liver tonic and leaves when made into paste were spread over externally to the forehead as an antidote for fevers ${ }^{8}$. Based on the above fact, the contemporary study was addressed to isolate and characterize bioactive compounds present in ethanolic flower extracts of $B$. tomentosa and to assess their in vivo anti-inflammatory and radical quenching abilities of crude and isolated compound in carrageenan induced paw oedema model.

\section{Materials and Methods}

\section{Study area}

Fresh flowers of B. tomentosa were harvested from the surrounding areas of Coimbatore district, Tamil Nadu, India. The authenticity of the selected plant material was duly identified and confirmed by comparison with reference specimen preserved at Botanical Survey of India, Southern Circle, Coimbatore. The voucher specimen (vide no: BSI/SC/5/23/08-09/Tech.-1719) were lodged in the departmental herbarium for further reference. The plant materials were cleaned, washed with copious amount of water, shade dried, chopped into bits and coarsely powdered in a Willy mill (Nippon Electricals, Chennai, India) to 60-mesh size for extraction.

\section{Preparation of crude plant extracts}

$50 \mathrm{~g}$ of coarsely powdered plant samples were exhaustively extracted with absolute ethanol after dewaxing with petroleum ether using soxhlet apparatus. The extracts were filtered and concentrated to dryness under reduced pressure using rotary vacuum evaporator (RE300; Yamato, Japan), lyophilized (4KBTXL-75; Vir Tis Benchtop K, New York, USA) to remove 
traces of water molecules and the lyophilized powders were stored at $-20^{\circ} \mathrm{C}$ until used directly for the isolation and assessment of anti-inflammatory activities.

\section{Isolation and characterization of bioactive principles}

The ${ }^{1} \mathrm{H}$ and ${ }^{13} \mathrm{C}$ NMR spectra were recorded on a Bruker DRX 500 instrument with TMS (Tetramethylsilane) as internal standard. Chemical shifts (ð) were expressed as parts per million (ppm). Mass data was measured on a QP 1000 Shimadzu (Japan) mass spectrometer. Infra-red (IR) related spectral data were recorded using Shimadzu FTIR-8400S spectrophotometer (Tokyo, Japan). Melting points were obtained on an X-4 digital display micromelting point apparatus. Column chromatography was performed using silica gel (60-120 mesh) (Merck). Fractions were monitored using TLC and spots were visualized using iodine chamber and UV lamp.

\section{Isolation, Purification and Identification}

The ethyl acetate soluble fractions $(50 \mathrm{~g})$ of ethanolic flower extracts of $B$. tomentosa were eluted with solvent systems of increasing polarity such as hexane (100\%), hexane: ethylacetate $(95: 5 ; 90: 10 ; 85: 15)$ and so on using column chromatography ${ }^{9}$ and these fractions were checked for purity by analytical TLC in an appropriate solvent systems and the zone was detected with a UV lamp and iodine chamber.

The compound was isolated from the ethanolic flower extract of $B$. tomentosa in the solvent systems of hexane: ethylacetate (90:10) in the form of yellow crystals (792mg). The molecular formula of the compound, $\mathrm{C}_{27} \mathrm{H}_{30} \mathrm{O}_{16}$ coincides with the molecular ion peak appeared in the mass spectrum (MW=610) (Fig 1). Melting point was $226 \sim 228^{\circ} \mathrm{C}$. IR spectrum showed a broad absorption peak at $3443.05 \mathrm{~cm}^{-1}$ which indicates the presence of hydroxyl groups and also the carbonyl group appeared at $1730.21 \mathrm{~cm}^{-1}$ (Fig 1). In ${ }^{13} \mathrm{C} \mathrm{NMR}$, sugar unit gives peaks at $\delta 45$ to $\delta 65$. The aromatic carbon appeared at $\delta 105.39$, oxygenated carbon at $\delta 156.24$ and carbonyl carbon at $\delta 179.55$ (Fig 2). ${ }^{1} \mathrm{H}$ NMR spectrum registered aliphatic protons at $\delta 0.67$ to $\delta 2.98$ and aromatic proton at $\delta 5.98$ to $\delta 8.26$ (Fig 2). The compound also displayed positive responses against aluminium chloride and shinoda test, the test for the confirmation of flavonoids. Based on comparison and upon close proximity with the preceding literature, the compound was identified as rutin (Fig 2).

\section{Structure of the compound}


The compound showed a single peak with retention time of $30.78 \mathrm{~min}$ in its HPLC chromatogram and showed that it is a pure compound (Table 3). The mass spectrum of the compound gave a pseudo molecular ion peak at $\mathrm{m} / \mathrm{z} 611$ for $[\mathrm{M}+\mathrm{H}]^{+}$ion and analyzed for a molecular formula of $\mathrm{C}_{27} \mathrm{H}_{30} \mathrm{O}_{16}$.

The NMR data of the compound depicting the structure of flavonoid were as follows ${ }^{1} \mathrm{H}-\mathrm{NMR}$ (500 MHz, DMSO-d6 ), $\delta$ ppm: 3.38-3.77 (m, 12H of sugar moieties), 4.39 and 5.63 each for one proton were attributed to the presence of two anomeric protons in the compound. The signal at $\delta 1.13$ is due to methyl group present in rhamnose sugar unit. The signals at $\delta 6.72$, $6.81,6.91,7.34$ and 7.91 were assigned to five protons of the aromatic ring system. The signals at $\delta 8.51$ and 9.91 are due to phenolic protons. Based on the mass spectral data and the NMR data the compound was identified as rutin.

\section{In vivo studies}

\section{Animals}

Male swiss albino mice (20-30g) and wistar strain albino rats (200-250g) were procured from the Small Animals Breeding Station, College for Veterinary and Animal Sciences, Kerala Agricultural University, Mannuthy, Kerala. They were housed in a well-ventilated polyacrylic cages $(38 \times 23 \times 10 \mathrm{~cm})$ with not more than six animals per cage and were maintained under standard environmental conditions $\left(14 \mathrm{~h}\right.$ dark/10h light cycle; Temp $25 \pm 2^{\circ} \mathrm{C}$; humidity $35-60 \%$; air ventilation) with standard pellet diet (M/s Hindustan Lever Ltd., Mumbai, India) and fresh water. All the animals were fasted overnight before the experimental schedule, but have free access for water ad libitum. The experiments conducted were approved by Institutional Animal Ethics Committee (IAEC) (Approval No: 659/02/a/CPCSEA) constituted under the guidelines of committee for the purpose of the control and supervision of experiments on animals (CPCSEA).

\section{Acute toxicity studies}

Acute oral toxicity study was carried out according to Organization for Economic Cooperation and Development (OECD) guidelines 423 (OECD, 1987). Male swiss albino mice with mass ranging from 20-30g were divided into 10 groups of 6 animals each. First group served as control and was treated with normal water. Group 2, 3, 4, 5, 6 and 7 were orally treated respectively with a dose of 100, 500, 1000, 2000 and $3000 \mathrm{mg} / \mathrm{kg}$ b.w. of ethanolic flower extract of B. tomentosa. Whereas group 8,9 and 10 were orally treated with a single dose of 
isolated compound, rutin at a dose range of $10,50,100 \mathrm{mg} / \mathrm{kg}$ b.w. respectively. Animals were observed at $0 \mathrm{~h}, 1 \mathrm{~h}, 2 \mathrm{~h}, 4 \mathrm{~h}, 6 \mathrm{~h}, 8 \mathrm{~h}, 24 \mathrm{~h}$ and $72 \mathrm{~h}$ after the administration of the drug (with special attention given during the first four hour). Observation was made for mortality and clinical signs, which include changes in skin, fur, eyes and mucous membranes. The gross behaviour like body positions, locomotion, rearing, tremors and gait were also noted. The effect of ethanolic plant extracts and its isolated compound, rutin on passivity, grip strength, pain response, stereotypy, vocalization, righting reflex, body weight and water intake were also observed $^{10}$.

\section{Anti-inflammatory activity}

Male wistar albino rats were divided into 5 groups of 6 animals each. The animals were fasted overnight prior to the start of the experimental schedule, but have free access for water $a d$ libitum. Group 1 served as normal control, while group 2 served as carrageenan intoxicated group (1\%). Groups 3 and 4 received ethanolic flower extract and isolated compound, rutin of B. tomentosa at the doses of 250 and $10 \mathrm{mg} / \mathrm{kg}$ b.w., respectively. Animals of group 5 received the standard anti-inflammatory drug, indomethacin (10mg/kg b.w.). Acute inflammation was produced by the subplantar administration of $0.1 \mathrm{~mL}$ of $1 \%$ carrageenan (in $1 \% \mathrm{CMC} \mathrm{w} / \mathrm{v}$ ) in the right hind paw of the rat of all the groups except group 1. The animals were pretreated with the extract/test drug $1 \mathrm{~h}$ before the administration of carrageenan. The thickness $(\mathrm{mm})$ of the paw was measured using Plethysmometer (Letica Scientific Instruments, Barcelona, Spain). The paw volume of the rats were measured at $0 \mathrm{~min}, 30 \mathrm{~min}, 60 \mathrm{~min}, 120 \mathrm{~min}$ and $240 \mathrm{~min}$ after the carrageenan injection and the paw oedema was calculated ${ }^{11}$.

\section{In vivo antioxidant studies}

The enzymic antioxidant activities viz., super oxide dismutase (SOD), catalase (CAT), glutathione peroxidase (GPx), glutathione-s-transferase (GST) and non-enzymic antioxidant activities viz., total reduced glutathione (GSH) and ascorbic acid (vitamin C) contents were assessed in tissue homogenates of hind paw samples as per the method adopted by Panda $(2012)^{12}$. Lipid peroxide (LPO) levels were determined according to the method adopted by Jiang $(1992)^{13}$.

\section{Statistical analysis}

All the experimental results were presented as Mean \pm SE (Standard Error) ( $n=6$ ) using Duncan's Multiple Range Test (DMRT). Statistical significance between the control and 
experimental groups were determined using one-way analysis of variance (ANOVA) by Tukey's multiple comparison range test (Graph pad prism 4.0 software). P-value of 0.001 $(\mathrm{P}<0.001)$ was determined to be awfully significant.

\section{Results and Discussion}

To explore the anti-inflammatory effect of crude ethanolic extract of $B$. tomentosa flower and its isolated compound, rutin in vivo, the carrageenan induced paw oedema model was commonly used which represents different phases of inflammation. Measurement with plethysmometer evoked the formation of paw swellings within half an hour after carrageenan challenge. Paw swelling increased dramatically after $2 \mathrm{~h}$ and persisted upto $4 \mathrm{~h}$ after carrageenan injection. Preadministration of rat with crude ethanolic flower extract and isolated compound, rutin $\left(250\right.$ and $10 \mathrm{mg} / \mathrm{kg}$ b.w.) significantly reduced the paw volume $(\mathrm{mm})$ after $3^{\text {rd }}$ and $4^{\text {th }}$ hours in comparison with that of the control group. Outwardly, the flower extract at $250 \mathrm{mg} / \mathrm{kg}$ b.w. revealed a significant decrease of oedema by $88.7 \%$ after $240 \mathrm{~min}$ of carrageenan treatment. The end result implies that the deprived activity unveiled by the flower extracts could be elucidated by the existence of lower contents of bioactive constituents and might necessitate immensely higher concentration to ensure striking effect. Rutin generated superior effects $(10 \mathrm{mg} / \mathrm{kg}$ b.w.) (92.6\%) which is often comparable with that of the standard drug, indomethacin (96.1\%) (Table 1). Evidently, the isolated compound, rutin (10mg/kg b.w) also evoked a discernable anti-inflammatory effect at 180min of post-carrageenan injection, which was greater than that engendered by indomethacin $(10 \mathrm{mg} / \mathrm{kg} \mathrm{b.w})$. This advocates that the antiinflammatory effect may implicates the inhibition of prostaglandin synthesis. The extract also prevented the formation of exudate and leucocytes mobilization and its responsible inflammatory stimuli.

The indigenous medicaments all over the world are currently revalued by an extensive activity of research on different plant species and their therapeutic principles. Experimental testimony recommends that free radical scavengers and reactive oxygen species (ROS) can be concerned with a huge number of ailments. It response with all other biological entities and ultimately prone to tissue damage ${ }^{14}$. In the current scenario, the radical quenching potential of the crude ethanolic extract of $B$. tomentosa flower and its isolated compound, rutin were gauged by means of various in vivo chemical assays. Carrageenan-induced hind paw oedema model was used for appraising the anti-inflammatory effect ${ }^{15,16,17}$. Administration of carrageenan into the plantar medium of the rat hind paw enlarged the paw diameter 
progressively over the period of six hours. In the present study, carrageenan induced rat displayed an extreme decline in in vivo antioxidant enzyme levels as compared with that of the normal control group. SOD and catalase levels condensed enormously $\left({ }^{\mathrm{a}} \mathrm{P}<0.001\right)$ pertaining to inflammation. As a result, treatment with ethanolic flower extract of $B$. tomentosa and its isolated compound, rutin provoked significant reinstatement of their levels to near normal values $\left({ }^{\mathrm{d}} \mathrm{P}<0.001\right)$. GPx activity also intensified consequently $\left({ }^{\mathrm{d}} \mathrm{P}<0.001\right)$ in groups of rats treated with $B$. tomentosa flower extract and rutin, when compared with inflammation control rat (Table 2). Seemingly, the isolated compound, rutin exposed distinctly more activity than their corresponding crude extract. Moreover, the isolated compound, rutin (10mg/kg b.w.) also demonstrated pronounced and effective activity in amending the oxidative repute to near normal level than that of the reference drug, indomethacin (10mg/kg b.w).

In the current study, in vivo antioxidant assay divulged a drastic upsurge in the activity of SOD, CAT, GST, GPx, Vit-C and GSH when governed with test drugs while LPO levels subsided dramatically. The isolated compound, rutin (10mg/kg b.w.) and ethanol flower extract (250mg/kg b.w.) exhibited greater quenching efficacy when compared to carrageenan control. Due to the defending action, the oral administration of crude ethanolic flower extract and its isolated compound evidenced to be esteemed auspicious entrants of quenching free radicals (Table 2). The significant capability of this flavonoid rich constituent is alleged to arise from its shielding effects by stabilising and counterbalancing the ROS which may support in upholding the free radical quenching arsenal and this infers that it is predominantly owing to the presence of flavonoid constituents present in it. The effect unveiled by the plant extract was comparable with that of the standard drug, indomethacin (10mg/kg b.w.).

Bauhinia tomentosa is an opulent source of inimitable natural products for the development of drugs in contradiction of innumerable diseases as well as for the growth of industrial products, which exerts numerous biological effects viz., antioxidant, antibacterial, antifungal, antihyperglycemic and antilipidemic, antiulcer, immunomodulatory and antiinflammatory activities ${ }^{18,19}$. It can be recognized that inflammation and oxidative stress have been allied as significant dynamics for the onset of innumerable ailments. A superfluous testimony had revealed that excess production of ROS befalls at the spots of inflammation and this subsidizes to complete tissue impairment. The synchronise activities of several cellular antiradicals in mammalian cells were precarious for effectually cleansing free radicals but surplus production of ROS leads to lipid peroxidation. Inflammatory retorts prompted by carrageenan in the current findings displayed a tremendous upsurge in NO and lipid 
peroxidation products and miserable antioxidant levels ${ }^{20,21,22}$. Furthermore, the compound, rutin was more protuberant and effectual in modifying the oxidative site to normal levels since it retain perfect structural chemistry for free radical quenching efficacy which is bestowed to be an efficacious antiradical quencher in $v i v o^{23}$. Rutin is formerly stated to possess pharmacological reputation primarily for its anti-inflammatory effect on arthritis ${ }^{24}$ and also for antifungal $^{25}$ anticancerous effect ${ }^{26,27}$, anti-hyperglycaemic and antioxidant activity ${ }^{28}$, reversed hepatotoxicity $^{29,30}$, prevent stroke, heart attack, cardiovascular diseases ${ }^{31,32}$. The flavonoid, rutin is extracted and isolated from the plant hinge on the divergences in solubility concentrations. It is used for the treatment of varied ailments allied with capillary bleeding and increased capillary permeability, thereby it reclaims the maladies associated with inflammation.

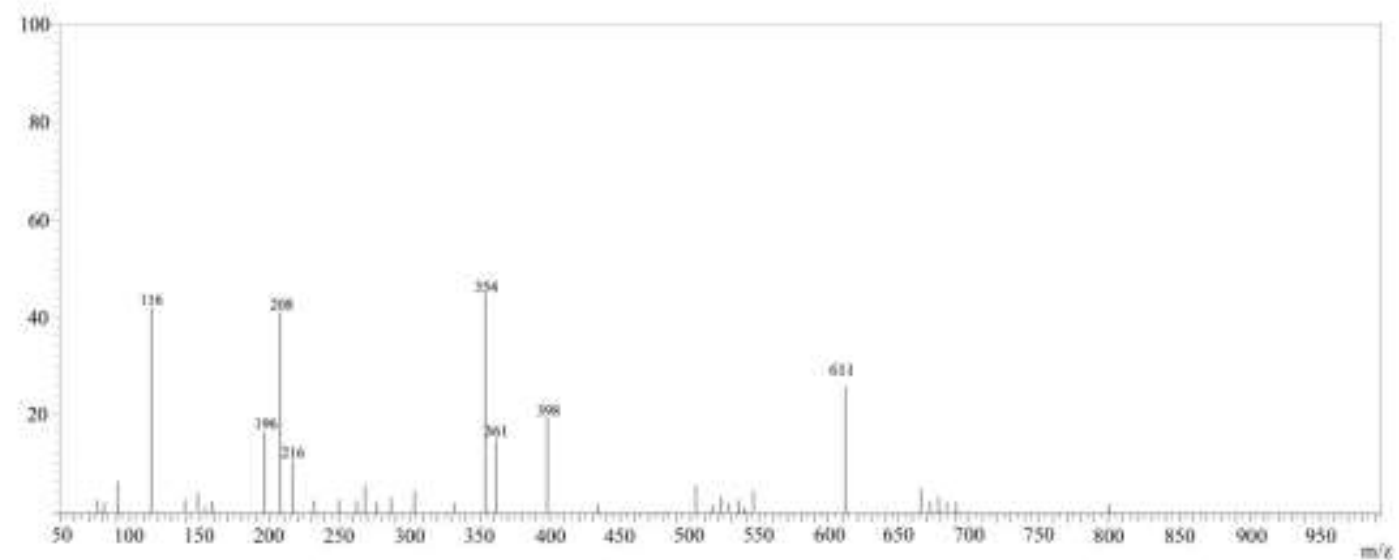

Mass spectrum 


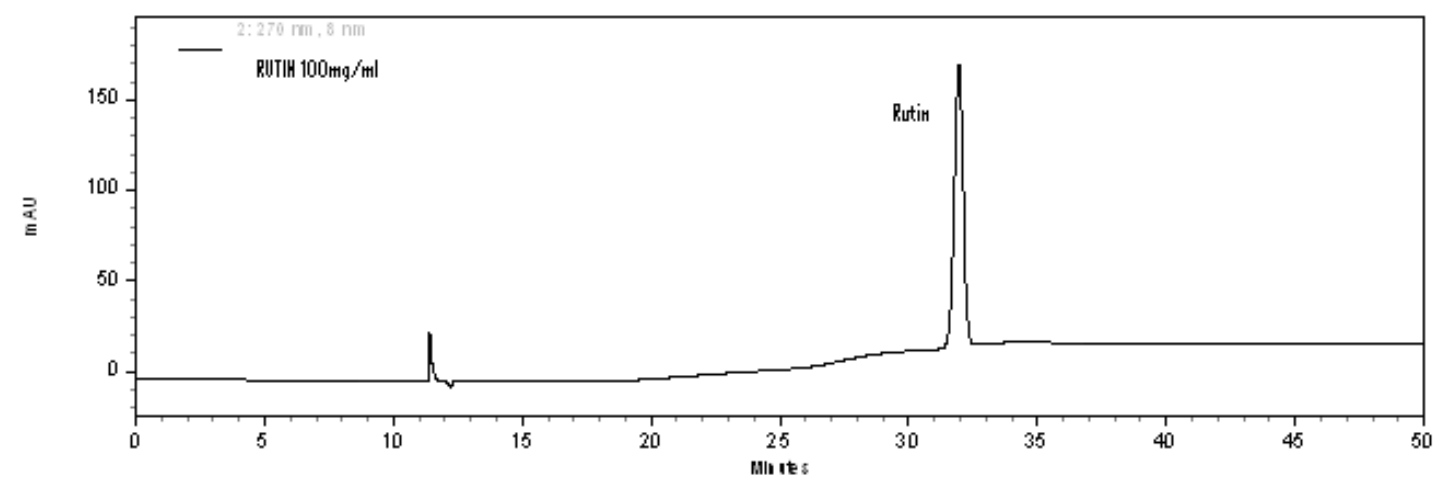

HPLC analysis

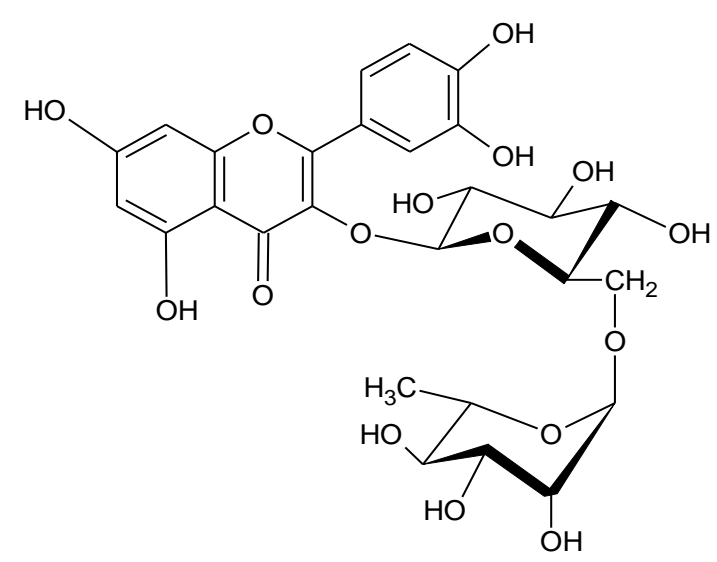

Structure of rutin

Fig: 1. Mass spectra, HPLC analysis and structure of the column purified compound, rutin isolated from the ethanolic flower extract of $B$. tomentosa. 


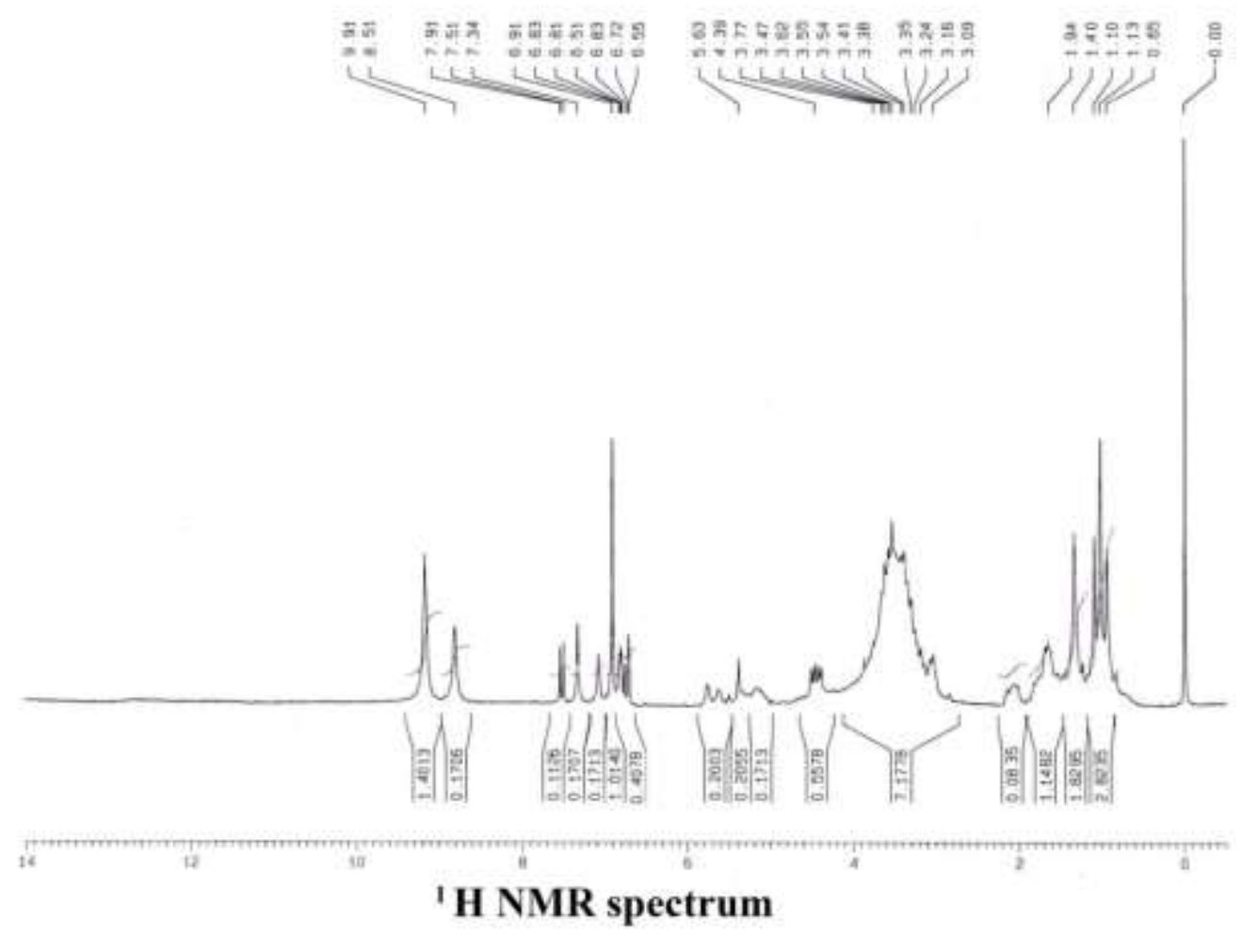

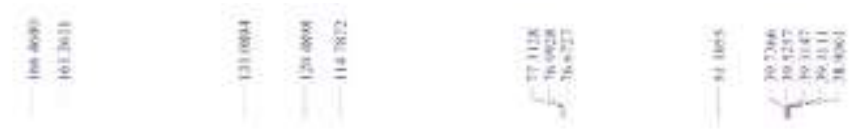

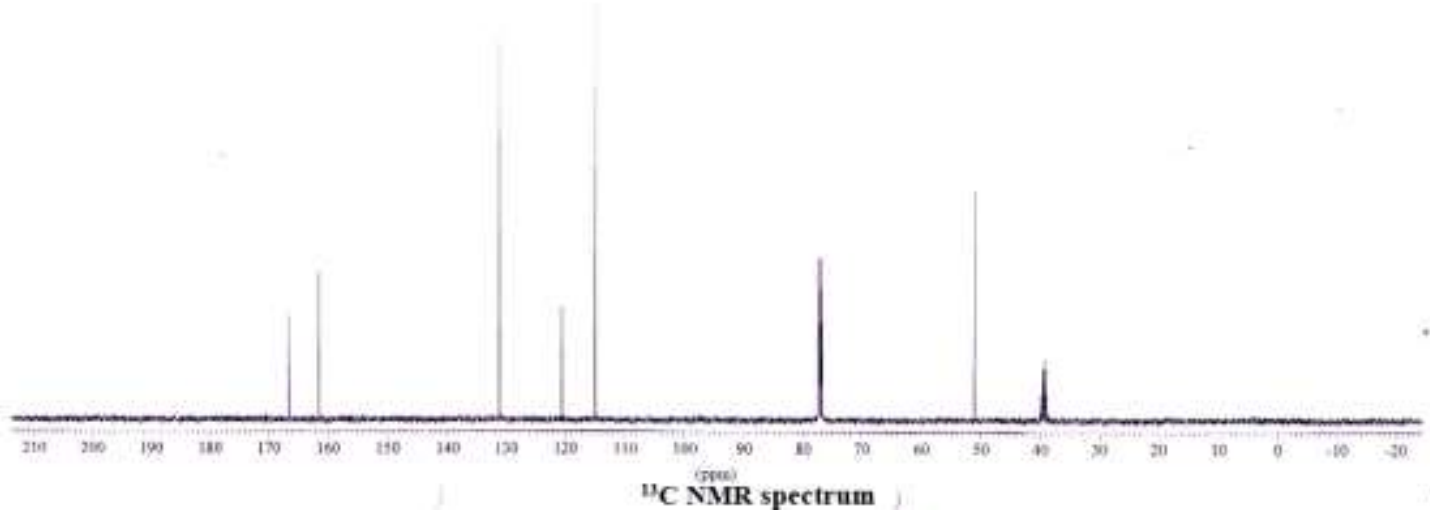

Fig: $2 .{ }^{13} \mathrm{C}$ and ${ }^{1} \mathrm{H}$ NMR spectra of the column purified compound, rutin isolated from the ethanolic flower extract of $B$. tomentosa. 
Table.1. Anti-inflammatory effect of crude ethanolic extract and its isolated compound, rutin of $\boldsymbol{B}$. tomentosa flower in carrageenan induced paw oedema model in rats.

\begin{tabular}{|c|c|c|c|c|c|c|c|}
\hline \multirow{2}{*}{$\begin{array}{l}\text { Treatment } \\
\text { group }\end{array}$} & \multicolumn{5}{|c|}{ Oedema induced by carrageenan } & \multirow{2}{*}{$\begin{array}{c}\text { Increase } \\
\text { in paw } \\
\text { volume } \\
\text { thickness } \\
\text { (mm) }\end{array}$} & \multirow{2}{*}{$\begin{array}{c}\text { Inhibition } \\
(\%)\end{array}$} \\
\hline & Omin & 60min & $120 \mathrm{~min}$ & 180min & $240 \mathrm{~min}$ & & \\
\hline Control & $1.188 \pm 0.1$ & $1.188 \pm 0.5$ & $1.189 \pm 0.4$ & $1.187 \pm 0.8$ & $1.188 \pm 0.8$ & - & - \\
\hline $\begin{array}{l}\text { Carragennan } \\
\text { induced }(1 \%)\end{array}$ & $1.196 \pm 0.8$ & $1.152 \pm 0.4$ & $1.573 \pm 0.8$ & $1.625 \pm 0.4$ & $1.149 \pm 1.1$ & 0.473 & - \\
\hline $\begin{array}{l}\text { B. tomentosa } \\
\text { flower } \\
\text { extract } \\
(250 \mathrm{mg} / \mathrm{kg} \\
\text { b.w.) }\end{array}$ & $1.146 \pm 0.9$ & $1.396 \pm 0.1^{b}$ & $1.348 \pm 0.1^{b}$ & $1.291 \pm 0.2^{b}$ & $1.199 \pm 0.6^{\mathrm{a}}$ & 0.053 & 88.7 \\
\hline $\begin{array}{l}\text { Rutin } \\
(10 \mathrm{mg} / \mathrm{kg} \\
\text { b.w) }\end{array}$ & $1.162 \pm 0.3$ & $1.403 \pm 0.3^{\mathrm{ns}}$ & $1.352 \pm 0.4^{b}$ & $1.298 \pm 0.2^{\mathrm{a}}$ & $1.197 \pm 0.4^{\mathrm{a}}$ & 0.035 & 92.6 \\
\hline $\begin{array}{l}\text { Indomethacin } \\
(10 \mathrm{mg} / \mathrm{kg} \\
\text { b.w) }\end{array}$ & $1.151 \pm 0.1$ & $1.336 \pm 0.8^{\mathrm{a}}$ & $1.324 \pm 0.7^{\mathrm{a}}$ & $1.312 \pm 0.1^{\mathrm{a}}$ & $1.149 \pm 1.1^{\mathrm{a}}$ & 0.018 & 96.1 \\
\hline
\end{tabular}

Values are mean \pm standard error mean (SEM) for six animals in each group $(n=6)$.

$* * \mathrm{P}<0.01^{\mathrm{a}} ; * \mathrm{P}<0.05^{\mathrm{b}}$ compared to corresponding control. 
Table.2. In vivo antioxidant status of crude ethanolic extract and its isolated compound, rutin of $B$. tomentosa flower in carrageenan induced paw oedema in rats.

\begin{tabular}{|l|l|l|l|l|l|}
\hline \multirow{2}{*}{ Parameters } & \multicolumn{5}{|c|}{ Carrageenan induced oedema } \\
\cline { 2 - 6 } & Normal & $\begin{array}{l}\text { Carrageenan } \\
\text { control }\end{array}$ & $\begin{array}{l}\text { Flower extract } \\
(250 \mathrm{mg} / \mathrm{kg} \\
\text { b.w })\end{array}$ & $\begin{array}{c}\text { Rutin } \\
(10 \mathrm{mg} / \mathrm{kg} \mathrm{b} . \mathrm{w})\end{array}$ & $\begin{array}{l}\text { Indomethacin } \\
(25 \mathrm{mg} / \mathrm{kg} \mathrm{b} . \mathrm{w})\end{array}$ \\
\hline LPO & $4.6 \pm 1.1$ & $13.9 \pm 1.0^{\mathrm{a}}$ & $6.7 \pm 0.2^{\text {ad }}$ & $6.1 \pm 0.1^{\text {ad }}$ & $4.9 \pm 1.1^{\mathrm{d}}$ \\
\hline SOD & $34.2 \pm 0.3$ & $18.9 \pm 2.5^{\mathrm{a}}$ & $17.9 \pm 2.9^{\mathrm{bd}}$ & $26.9 \pm 0.6^{\mathrm{d}}$ & $30.9 \pm 2.1^{\mathrm{d}}$ \\
\hline CAT & $48.6 \pm 0.6$ & $27.5 \pm 0.2^{\mathrm{a}}$ & $28 \pm 0.1^{\mathrm{cd}}$ & $38.3 \pm 0.1^{\mathrm{d}}$ & $46.3 \pm 0.2^{\mathrm{d}}$ \\
\hline GPx & $5.2 \pm 0.1$ & $1.3 \pm 0.2^{\mathrm{a}}$ & $2.5 \pm 1.4^{\mathrm{d}}$ & $3.0 \pm 0.9^{\mathrm{d}}$ & $4.7 \pm 0.1^{\mathrm{d}}$ \\
\hline GST & $5.7 \pm 0.4$ & $2.6 \pm 0.2^{\mathrm{a}}$ & $2.9 \pm 0.1^{\mathrm{c}}$ & $3.7 \pm 0.7^{\mathrm{d}}$ & $4.8 \pm 0.2^{\mathrm{d}}$ \\
\hline Vitamin C & $7.6 \pm 0.3$ & $1.9 \pm 0.1^{\mathrm{a}}$ & $3.2 \pm 0.5^{\mathrm{d}}$ & $5.1 \pm 0.3^{\mathrm{d}}$ & $6.4 \pm 0.4^{\mathrm{d}}$ \\
\hline GSH & $6.2 \pm 2.1$ & $2.2 \pm 1.2^{\mathrm{a}}$ & $3.7 \pm 0.2^{\mathrm{ce}}$ & $5.7 \pm 1.9^{\mathrm{d}}$ & $5.9 \pm 8.4^{\mathrm{d}}$ \\
\hline
\end{tabular}

LPO (Lipid peroxidation) expressed as $\mu$ moles of malondiadehyde (MDA)formed /mg protein; SOD (Superoxide dismutase) expressed as units /mg protein; CAT (Catalase) expressed as $\mu$ moles of hydrogen peroxide consumed/min/mg protein; GPx (Glutathione peroxidase) expressed as $\mu$ moles of reduced glutathione utilized/min/mg protein; GST (Glutathione $-\mathrm{S}-$ transferase) expressed as units/ mg protein; Vitamin C (Ascorbic acid) contents expressed as $\mu$ moles/mg protein; GSH (Reduced glutathione) expressed as $\mu$ moles/mg protein.

${ }^{\mathrm{a}} \mathrm{P}<0.001 ;{ }^{\mathrm{b}} \mathrm{P}<0.01 ;{ }^{\mathrm{c}} \mathrm{P}<0.05$, significantly different from the control group.

${ }^{\mathrm{d}} \mathrm{P}<0.001 ;{ }^{\mathrm{e}} \mathrm{P}<0.01 ;{ }^{\mathrm{f}} \mathrm{P}<0.05$, significantly different from the inflammed control groups

Table.3. HPLC analysis of crude ethanolic extract and its isolated compound, rutin of Bauhinia tomentosa.

\begin{tabular}{|l|l|l|l|l|l|}
\hline $\begin{array}{l}\text { Peak } \\
\text { No }\end{array}$ & $\begin{array}{l}\text { Identity( PDA } \\
\text { Confirmed) }\end{array}$ & Retention Time & Height & Area & Concentration \\
\hline 1 & Rutin & 30.78 & 5689124 & 245696847 & $96.85 \%$ \\
\hline
\end{tabular}




\section{Conclusion}

Therefore to conclude, the contemporary findings evidently deliberates the fact that $B$. tomentosa, a flavonoid rich plant have subsidised an immense influence on anti-inflammatory, antioxidant, and cytotoxic activities accompanied with their traditional assertions. The compound, rutin isolated from ethanolic flower extract of $B$. tomentosa have reputed to possess potent anti-inflammatory activity and molecular intention based formulations, pursuing significant molecular trails, along with radical quenching efficacies. Postulated the aforementioned testimony, it is enticing to envisage that the isolated compound, rutin may leads to the progression of novel non-steroidal anti-inflammatory drugs. Furthermore, the bioactive entities found in the study species, $B$. tomentosa have an eclectic relevance in biomedicines.

Conflict of Interest: The author reports no conflict of interest.

\section{Acknowledgement}

\section{References}

1. Jixin Zhong, Guixiu Shi. Regulation of inflammation in chronic disease: Frontiers in immunology, 2019; 10: 737.

2. Kunnumakkara AB, Sailo BL, Banik K. Chronic Diseases, inflammation and spices: how are they linked?: Journal of Translational Medicine, 2018; 16: 14.

3. Galvao I, Sugimoto MA, Vago JP, Machado MG, Sousa LP. Mediators of Inflammation: Immuno Pharmacology and Inflamation, 2018; 3-32.

4. Machado GC, Abdel-Shaheed C, Martin U, Richard OD. Non-steroidal Antiinflammatory Drugs (NSAIDS) for Musculoskeletal Pain: British Medical Journal, 2021; 372: n104.

5. Clara dos Reis Nunes, Mariana Barreto Arantes, Silvia Menezes de Faria Pereira, Larissa Leandro da Cruz, Michel de Souza Passos, Luana Pereira de Moraes, Ivo José Curcino Vieira, Daniela Barros de Oliveira. Plants as Sources of Anti-Inflammatory Agents: Molecules, 2020; 25(16): 3726.

6. Sankara Rao, K., Raja K Swamy, K. Deepak, R. Arun Singh, K. Gopalakrishna Bhat. Flora of Peninsular India. 2019. http://peninsula.ces.iisc.ac.in/plants.php? 
7. Akbar S. Bauhinia tomentosa L./ Bauhinia variegate L. (Fabaceae/ Leguminosae): Handbook of 200 Medicinal Plants, 2020; 413-419.

8. Arvind N, Sharma N, Singh M. F. Spectrum of Pharmacological Activities from Bauhinia variegata: A Review. Journal of Pharmacy Research, 2012; 5(2): 792-797.

9. Reid RG, Sarker SD. Isolation of Natural Products by Low-Pressure Column Chromatography. In: Sarker S., Nahar L. (eds) Natural Products Isolation: Methods in Molecular Biology, 2012; 864: 155-187.

10. Lipnick RL, Cotruvo JA, Hill RN, Bruce RD, Stitzel KA, Walker AP, Chu I, Goddard M, Segal L, Springer JA, Myers RC: Comparison of the up-and-down, conventional LD50 and fixed dose acute toxicity procedures: Fundamental and Chemical Toxicology, 1995; 33: $223-231$.

11. Vasudevan M, Gunnam KK, Parle M. Antinociceptive and anti-inflammatory properties of Daucus carota seeds extract: Journal of Health Science, 2006; 52: 598606.

12. Panda, SK. Assay guided comparison for enzymatic and non-enzymatic antioxidant activities with special reference to medicinal plants: Antioxidant Enzyme, 2012; 14: 381-400.

13. Jiang ZY, Hunt JV, Wolf SP. Ferrous ion oxidation in the presence of xylenol orange for detection of lipid hydroperoxide in low density lipoprotein: Analytical Biochemistry, 1992; 202, 384-389.

14. Karthika K, Jamuna S, Abinaya G, Venkatachalapathi A, Thenmozhi K, Paulsamy S. Evaluation of Anti-inflammatory and Antioxidant Properties of Crude Extract and Forskolin from Solena amplexicaulis Leaf: Indian Journal of Pharmaceutical Sciences, 2016; ss78 (3): 377-387.

15. Ou Z, Zhao J, Zhu L, Huang L, Ma Y, Ma C, Luo C, Zhu Z, Yuan Z, Wu J, Li R, Yi J. Anti- inflammatory effect and potential mechanism of Betulinic acid on $\lambda$ Carragennan-induced paw edema in mice: Biomedicine and pharmacotherapy, 2019; $118: 109347$.

16. Chauhan P, Singh S, Gupta YK, Kumar U. Evaluation of toxicity studies and antiinflammarory activity of Terminalia bellerica in carragennan-induced paw edema in experimental rats: Journal of Natural Science, Biology and Medicine, 2018; 9: 169-74.

17. Pradnya, Anasane D, Alka C: Evaluation of anti-inflammatory effects if Ficus hispida L. leaves extract against Carrageenan induced Paw Edema in Rats: Journal of Pharmaceutical Science and Research, 2017; 9(4): 364-367. 
18. The wealth of India, Raw materials. Publication and information directorate, CSIR New Delhi, In: Ambasta SP (ed.) Vol. 2 B, 1998: 56-57.

19. http:/www.flowersofindia.net/catalog yellow orchid tree.html.

20. Abbas SS, Schaalan MF, Bahgat AK and Ezzeddin SED. Possible potentiation by certain antioxidants of the anti-inflammatory effects of diclofenac in rats: The Scientific World Journal, 2014; 9 pages, Article ID 731462.

21. Arora N, Shashi PR. GC-MS analysis of the essential oil of Celastrus paniculatus Wild. seeds and antioxidant: anti-inflammatory study of its various solvent extracts: Industrial Crops and Products, 2014: 61, 345-351.

22. Benayad Z, Cristina MV, Frias J, Carmen GC, Eddine NES. Phenolic composition, antioxidant and anti-inflammatory activities of extracts from Moroccan Opuntia ficusindica flowers obtained by different extraction methods: Industrial Crops and Products, $2014 ; 62,412-420$.

23. Weixue D, Dejing C, Zhiyuan C, Haiyan S, Zhimin X. Antioxidant capacity differences between the major flavonoids in cherry (Prunus pseudocerasus) in vitro and in vivo models: LWT - Food Science and Technology, 2021; 141, 110938.

24. Felipie T, Mariana C, Fernanda JC, David DCM, Alexandre K, Fernando C, Marcelo VF, Angelo P, Frederico V, Costa S. Oral treatments with a flavonoid - enriched fraction from Cecropia hololeuca and with rutin reduce articular pain and inflammation in murine zymosan-induced arthritis: Journal of Ethnopharmacology, 2020; 260, 112841.

25. Oliveira VM, Carraro E, Auler ME, Khalil NM. Quercetin and rutin as potential agents antifungal against Cryptococcus spp.: Brazilian Journal of Biology, 2016; 4: 76.

26. Imani A, Maleki N, Bohlouli S, Kouhsoltani M, Sharifi S, Maleki Dizaj S. Molecular mechanisms of anticancer effect of rutin: Phytotherapy Research, 2020; 35.

27. Saleh A, ElFayoumi HM, Youns M. Rutin and orlistat produce antitumor effects via antioxidant and apoptotic actions: Naunyn-Schmiedeberg's Arch Pharmacol, 2019; 392: $162-175$.

28. Netaji TN, Ansar AS, Suresh RN. Anti-hyperglycemic activity of rutin in streptozotocin-induced diabetic rats: an effect mediated through Cytokines, antioxidants and lipid biomarkers: NISCAIR-CSIR, India, 2014; 720-727.

29. Choi Y, Seo H, Cho M, Kim J, Chung HS, Lee I, Kim MJ. Rutin inhibits DRP1mediated mitochondrial fission and prevents ethanol-induced hepatotoxicity in HepG2 cells and zebra fish: Animal Cells and Systems, 2021; 25: 1, 74-81. 
30. Hafez MM, Al-Harbi NO, Al-Hoshani AR, Al-Hoshani KA, Al Shrari SD, Al-Rejaie SS, Syed- Ahmed MM, Al-Shabanah OA. Hepato-protective effect of rutin via IL6/STAT3 pathway in $\mathrm{CCl}_{4}$ - induced hepatotoxicity in rats: Biological Research, 2015; 48:30.

31. Lin LV, Yucai Y, Gang Z, Guiyue Z. Rutin Inhibits coronary heart disease through ERK1/2 and Akt signalling in a porcine model: Experimental and Therapeutic Medicine, 2018; 15(1): 506-512.

32. Saklani RS, Gupta K, Mohanty IR. Cardioprotective effects of rutin via alteration in TNF-a, CRP, and BNP levels coupled with antioxidant effect in STZ-induced diabetic rats: Molecular and Cellular Biochemistry, 2016; 420: 65-72. 